\title{
Los múltiples enfoques de la investigación sociológica
}

\author{
ÓSCAR SANTACREU FERNÁNDEZ \\ INSTITUTO UNIVERSITARIO DE DESARROLLO SOCIAL Y PAZ
}

La Revista Obets cumple con este número su primer año de existencia. Desde su nacimiento, la revista tiene como objetivo ofrecer una plataforma a través de la cual los investigadores puedan dar a conocer los resultados de sus trabajos sobre las realidades sociales en el ámbito nacional e internacional, desde un planteamiento abierto a las novedades en el que se prioriza tanto la solidez como la originalidad de las aportaciones. Dentro del espíritu divulgador de la revista, el equipo de redacción ha optado desde el principio por facilitar la accesibilidad a la revista al incorporar en todos sus artículos la licencia Creative Commons (Reconocimiento-no comercial). Ello implica una conveniente protección de los derechos de autor al tiempo que los contenidos de la revista pueden copiarse, distribuirse o comunicarse públicamente, bajo las condiciones generales de reconocimiento de los créditos de la obra y la limitación a usos no comerciales.

En su primer número, publicado en junio de 2008, la atención se centró en el estudio de las Familias Multiculturales, recogiendo los resultados de diversas investigaciones realizadas en Europa sobre el análisis de las relaciones interculturales y que fueron presentadas durante el Seminario Interacciones Culturales. Relaciones de Género en los Espacios de Convivencia Intercultural de las Familias Mixtas, organizado por el Instituto Universitario de Desarrollo Social y Paz, y financiado por el Instituto de la Mujer, el Ministerio de Asuntos Sociales y el Vicerrectorado de Extensión Universitaria de la Universidad de Alicante. El segundo número de la revista presentó, junto a otros temas, una selección de artículos sobre juventud, profundizando en aspectos como la participación social de los jóvenes, formas de participación institucionalizada, producción de nuevos órdenes en sus prácticas sociales, etc.

La necesidad de interpretar el significado y la magnitud de los procesos sociales objeto de estudio, así como el análisis de sus implicaciones, está caracterizada cada vez más por una complejidad que no deja de crecer y por la aparición de nuevos enfoques, tanto teóricos como empíricos y/o de análisis. En este sentido, los modelos estructurales son un recurso útil, en el sentido de que permiten trabajar sobre una explicación narrativa compleja de la realidad, basada en el establecimiento de un sistema de relaciones explicativas entre variables que contempla tanto relaciones unidireccionales como bidireccionales, así como efectos directos, indirectos y condicionales. Evidentemente, para establecer estas relaciones los modelos estructurales han de incorporar un contenido teórico.

En cierto modo, podríamos decir que toda investigación aplicada ha de tomar en consideración tanto lo empíreo (el mundo de las ideas) como lo empírico (lo fundado en la experiencia). Así, por ejemplo, la utilización de modelos estructurales debe partir de un planteamiento teórico que implica la correcta elección y definición 
del tema de estudio, un repaso al estado actual de la cuestión y la operativización de los conceptos que intervienen en el mismo y de las fuentes de datos a utilizar. Sólo a partir de este análisis se podrá construir una explicación sociológica que incorpore hipótesis causales sobre las variables que intervienen en el objeto de estudio.

La edición actual de la revista integra un conjunto de artículos sobre metodología e investigación de alto contenido empírico, sin olvidar las aportaciones teóricas. Así, vamos a encontrar un primer grupo de trabajos que se basa, precisamente, en la aplicación de los modelos estructurales para el análisis de diferentes realidades sociales. El texto La imagen de los "hechos sociales" en la Sociología, de Antonio Alaminos, plantea, a partir de una reflexión sobre la percepción de la realidad, los sistemas de medición y de cifrado y los conceptos Etic y Emic como perspectivas de aproximación a la realidad, una serie de paralelismos entre el cubismo sintético y la aproximación metodológica mediante modelos estructurales a la realidad social.

Dentro también de este primer bloque, la revista incorpora una selección de los trabajos presentados en las VI Jornadas Internacionales El Modelado Estructural en el Estudio de la Realidad Social, Modelos de difusión de la incertidumbre: Impacto en la vida cotidiana, celebradas en Alicante del 28 de mayo al 10 de junio de 2009. El trabajo presentado por Antonio Luís Vicente y María Teresa Moreno, centrado en el estudio de la identidad nacional, realiza un análisis de la formación de identidades mediante un modelo estructural que pone en relación la formación de la identidad nacional con otras formas de identidad que toman como base otros ámbitos territoriales y políticos, como el ámbito europeo, la comunidad autónoma o la ciudad, así como otros elementos culturales como la utilización de una o más lenguas en el hogar. La metodología empleada por José Sabariegos en su trabajo sobre Participación Social también está basada en el uso de modelos estructurales de covarianzas, analizando no sólo los objetivos que dirigen la participación social sino también los factores que llevan a las personas a integrarse en el conjunto, como pueden ser la educación, la clase social, la educación o la orientación ideológica.

El segundo grupo de artículos incluido en este número aborda diferentes temáticas. Así, el artículo de Francisco José Francés Elementos para el estudio de la estratificación social en las sociedades avanzadas: estrategias operativas aporta una serie de propuestas operativas para el análisis de la estratificación social en lo que supone un esfuerzo de síntesis de los diferentes enfoques que la tradición sociológica ha ido aportando. Sin duda, el estudio de la estructura social ha de tener en cuenta las nuevas pautas de movilidad social en las sociedades avanzadas. Por otro lado encontraremos el texto firmado por Antonio Alaminos, Cristina López, Begoña López, Ignacia Perea y Óscar Santacreu, que supone una aproximación a la noción de las denominadas migraciones circulares como procedimiento de racionalización de las migraciones laborales que incorpore la noción de regreso, a fin de reintegrar en las sociedades de origen el capital humano formado y cualificado de modo que se mejore tanto el desarrollo social y económico en estas sociedades como la calidad de vida emocional de los migrantes y sus familias. 
Por último, la presente edición de Revista Obets. Revista de Ciencias Sociales incluye recensiones de dos libros. La primera de ellas, elaborada por Francisco Francés a partir del libro de Thomas J. Fararo (2001) Social Action Systems: Foundation and Synthesis in Sociological Theory, editado por Praeger Publishers, plantea una revisión general de la producción teórica en Sociología con un enfoque relacional a partir de las ideas básicas de cada corriente teórica. La segunda recensión, elaborada por Maximiliano Korstanje (Universidad de Palermo, Argentina), se centra en el texto de Malcolm Bull (1998) La Teoría del Apocalipsis y los fines del Mundo, en el que se analiza cómo la mayoría de las sociedades han interpretado la idea del Fin de los Tiempos, así como su influencia en los autores milenaristas.

Dado el carácter multidisciplinar de la revista, lectores, académicos y estudiantes de Ciencias Sociales tienen abierta en ella una ventana para la reflexión y aporte de sus trabajos e investigaciones. 